\title{
Actinobacteria for sustainable agriculture
}

\begin{abstract}
Actinobacteria is a phylum and class of Gram-positive bacteria. The phylum Actinobacteria are classified into six classes namely Acidimicrobiia, Actinobacteria, Coriobacteriia, Nitriliruptoria, Rubrobacteria and Thermoleophilia. Members of phylum Actinobacteria are ubiquitous in nature. Actinobacteria can be utilized as biofertilizers for sustainable agriculture as they can enhance plant growth and soil health though different plant growth promoting attributes such as solubilization of phosphorus, potassium and zinc, production of Fe-chelating compounds, phytohormones hormones such indole acetic acids, cytokinin, and gibberellins as well as by biological nitrogen fixation. The Actinobacteria also plays an important role in mitigation of different abiotic stress conditions in plants. The members of phylum Actinobacteria such as Actinomyces, Arthrobacter, Bifidobacterium, Cellulomonas, Clavibacter, Corynebacterium, Frankia, Microbacterium, Micrococcus, Mycobacterium, Nocardia, Propionibacterium, Pseudonocardia, Rhodococcus, Sanguibacter and Streptomyces exhibited the multifarious plant growth promoting attributes and could be used as biofertilizers for crops growing under natural as well as under the abiotic stress conditions for plant growth and soil health for sustainable agriculture.
\end{abstract}

Keywords: abiotic stress, actinobacteria, plant growth promotion, soil health, sustainable agriculture

\section{Introduction}

The plant microbiomes (epiphytic, endophytic and rhizospheric) have been isolated and have ability to promote plant growth are referred as plant growth-promoting (PGP) microbes. The plant microbiomes have been sorted out from diverse sources belongs to all three domian archaea, bacteria and fungi. Among three domain systems the members of domain bacteria are well characterized and reported as from diverse abiotic stresses, such as alkaline soil, $, 1,2$ saline soil, ${ }^{3}$ acidic soil ${ }^{1}$ low temperature ${ }^{4-11}$ high temperature, ${ }^{12-17}$ and drought. ${ }^{1}$ Among all three domain, there are very few report on archaea as plant growth promotion such as halophilic archaea including Natronoarchaeum, Natrinema, Natrialba, Haloterrigena, Halostagnicola, Halolamina, Haloferax, Halococcus, Halobacterium and Haloarcula having phosphorus solubilizing attributes under the hypersaline conditions. ${ }^{3,18}$

The microbes associated the plant rhizosphere are termed as rhizospheric microbes and rhizospheric actinobacteria are most dominant in nature. The study of different microbial diversity in form of plant microbiomes it can be concluded the members of phylum actinobacteria has been reported from different genera such as Streptomyces, Sanguibacter, Rhodococcus, Pseudonocardia, Propionibacterium, Nocardia, Mycobacterium, Micrococcus, Microbacterium, Frankia, Corynebacterium, Clavibacter, Cellulomonas, Bifidobacterium, Arthrobacter, Actinomyces, and Acidimicrobium. ${ }^{19}$ Actinobacteria have been represents a large portion of soil microbiomes in the plant root systems. ${ }^{20-24}$ The Actinobacteria has been isolated from diverse sources study e.g. chickpea (Cicer arietinum), ${ }^{25,26}$ maize (Zea mays), ${ }^{23,27,28}$ pea (Pisum sativum), ${ }^{24,29,30}$ rice (Oryza sativa), ${ }^{21,31,32}$ soybean (Glycine max), ${ }^{24,33-35}$ Sugarcane (Saccharum officinarum), ${ }^{36-38}$ sunflower (Helianthus annuus), $22,39,40$ and wheat (Triticum aestivum). ${ }^{41-46}$

The Gram-positive organisms with a high $\mathrm{G}+\mathrm{C}$ content belong to phylum Actinobacteria, constitute one of the largest phyla within the domain bacteria and consist of six classes namely, Thermoleophilia, Rubrobacteria, Nitriliruptoria, Coriobacteriia, Actinobacteria, and Acidimicrobiia, 3900 distinct species of 391 genera belonging to 67 families of 29 orders. ${ }^{19}$ Among 3900 distinct species of actinobacteria,
Volume 6 Issue I - 2019

\author{
Neelam Yadav, ' Ajar Nath Yadav ${ }^{2}$ \\ 'Gopi Nath PG College,Veer Bahadur Singh Purvanchal \\ University, India \\ ${ }^{2}$ Department of Biotechnology,Akal College of Agriculture, \\ Eternal University, India
}

\begin{abstract}
Correspondence: Neelam Yadav, Department of Biotechnology, Akal College of Agriculture, Eternal University, Sirmour-|73101, India, Tel 91-9882545085,
\end{abstract}

Emailneelamanyadav@gmail.com

Received: January II, 2019 | Published: February 18, 2019 thirty genera namely Streptosporangium, Streptomyces, Saccharothrix, Saccharopolyspora, Rhodococcus, Pseudonocardia, Nonomuraea, Nocardiopsis, Nocardioides, Nocardia, Mycobacterium, Micromonospora, Microbacterium, Leucobacter, Kribbella, Kocuria, Kitasatospora, Gordonia, Geodermatophilus, Corynebacterium, Cellulomonas, Brevibacterium, Brachybacterium, Bifidobacterium, Arthrobacter, Amycolatopsis, Agromyces, Actinoplanes, Actinomyces, and Actinomadura. Among all genera Streptomyces have been most dominant with 961 disticnt species followed by Mycobacterium (186 species). ${ }^{19}$

Microbes and their applications as bioinoculants have strategies to increase the current crops for sustainable agriculture. Microbes as bioinoculants and biopesticides are an alternative to chemical fertilisers to reduced environmental pollutions. The microbes having the plant growth promoting attributes such as nitrogen fixation and other plant growth promoting attributes such as solubilization of micronutrients phosphorus, potassium and zinc and production of Fe-chelating compounds, phytohormones. The nitrogen fixing actinobacteria such as Agromyces sp. ORS 1437, ${ }^{47}$ Arthrobacter humicola IARI-IIWP-42, ${ }^{48}$ Arthrobactermethylotrophus IARIHHS1-25, ${ }^{49}$ Arthrobacter nicotinovorans IARI-HHS1-1 49, Corynebacterium sp. AN1, ${ }^{50}$ Microbacterium ${ }^{51}$ Microbacterium FS-01, ${ }^{52}$ and Pseudonocardia dioxanivorans CBI190, ${ }^{53}$ have been isolated from the rhizosphere of various crops, which contribute fixed nitrogen to the associated plants.

Phosphorus is an essential element for the establishment and development of plants because it improves the entire root system, consequently improving the shoot. Phosphate solubilization is a common trait among microbes such as archaea, bacteria and fungi. There are many reports on PGP Actinobacteria with phosphate solubilizing attributes and a vast numbers of P-solubilizing microbes have been reported which include members belonging to Streptomyce djakartensis TB-4, Streptomyces sp. WA-1, ${ }^{54}$ Micrococcus SP N11- 0909, ${ }^{55}$, Microbacterium FS-01 52, Cellulosimicrobium sp. PB-09, ${ }^{56}$ Arthrobacter agilis strain L77, ${ }^{57}$ Micrococcus luteus IARITHW-25, ${ }^{58}$ Arthrobacter humicola IARI-IIWP-42, Micrococcus luteus IARI-IHD-5, Micrococcus sp. IARI-IIWP-20 48, Arthrobacter methylotrophus IARI-HHS1-25, Arthrobacter nicotinovorans IARI- 
HHS1-1, and Kocuria kristinae IARI-HHS2-64 49. Along with the phosphorus solubilization, potassium solubilization is also help for plant growth promotion and there are many reports on potassium solubilizing Actinobacteria such as Arthrobacter sp. 42, Arthrobacter sp. 4, and Microbacterium FS- $01 .{ }^{52}$ The ability to synthesize phytohormones is widely distributed among plant-associated bacteria and indole acetic acids may potentially be used to promote plant growth or suppress weed growth. There are many reports on production of phytohormones by Actinobacteria including Micrococcus SP N110909 55, Cellulosimicrobium sp. PB-09 56, Arthrobacter sp. AS, ${ }^{18,59}$ Micrococcus luteus IARI-THW-25, ${ }^{58}$ Micrococcus luteus IARIIHD-5, Micrococcus sp. IARI-IIWP-20, Arthrobacter humicola IARIIIWP-42, Kocuria sp. IARI-IHD-9 48, Arthrobacter methylotrophus IARI-HHS1-25, Arthrobacter nicotinovorans IARI-HHS1-1, Kocuria kristinae IARI-HHS2-64 49, Micrococcus luteus IARI-NIAW1-1, Arthrobacter sp. IARI-NIAW1-4, Micrococcus luteus IARI-NIAW1-1 $60 . .^{60-67}$

Iron is an essential nutrient for virtually all organisms and a necessary co-factor for many enzymatic reactions. The Fechelating compounds producing microbes shows for both direct and indirect enhancement of plant growth by beneficial Actinobacteria including Streptomyces, Micrococcus, Microbacterium, Kocuria, Corynebacterium, and Arthrobacter. ${ }^{56-60}$ There are many insecticidal compounds spinosyns, polynactins, milbemycin, emamectin, avermectin, and abamectin, have been reported to produced by Actinomycetes and applied for the biocontrol of insect. ${ }^{61-65}$ Termites are the most problematic pest threatening agriculture and the urban environment. They cause significant losses to annual and perennial crops. They are responsible for the loss of $15-25 \%$ of maize yield and about 1478 million Rupees. ${ }^{66}$ Most tropical crops are susceptible to termite attack worldwise, which included wheat, tomato, tobacco, tea, sunflower, sugarcane, soybean, rice, potatoes, pigeon pea, pearl millet, mulberry, mango, maize, groundnut, eucalyptus, cowpea, cotton, citrus, chickpea, beans, barley, banana, and almond. ${ }^{67}$ The pest management by microbes are effective, eco-friendly, economically viable, and socially acceptable method for sustainable agriculture and environments. ${ }^{67}$

\section{Conclusion}

The need of today's world is high output yield and enhanced production of the crop as well as fertility of soil to get in an ecofriendly manner. Actinobacteria should be explored for the use of bio-inoculants for different crops growing under the abiotic stresses such as temperature, $\mathrm{pH}$, drought and salinity. In view of the medical, biotechnological, and ecological importance of the Actinobacteria, an understanding of the evolutionary relationships among members of this large phylum and what unique biochemical or physiological characteristics distinguish species of different classes of Actinobacteria is of great importance and significance. The members of Actinobacteria can be applied for biofortification of minerals for different cereal crops as well as many most dominant Actinobacteria can be used as probiotics as functional foods for human health.

\section{Acknowledgments}

None.

\section{Conflicts of interest} work.

All authors declare that they have no conflicts of interest to this

\section{References}

1. Yadav AN, Verma P, Kumar M, et al. Diversity and phylogenetic profiling of niche-specific Bacilli from extreme environments of India. Ann Microbiol. 2015;65(2):611-629.

2. Saxena AK, Yadav AN, Rajawat M, et al. Microbial diversity of extreme regions: An unseen heritage and wealth. Indian J Plant Genet Resour. 2016;29(3):246-248.

3. Yadav AN, Sharma D, Gulati S, et al. Haloarchaea endowed with phosphorus solubilization attribute implicated in phosphorus cycle. Sci Rep. 2015;5:12293.

4. Yadav AN, Verma P, Sachan SG, et al. Indian cold deserts: Exploration of bacterial diversity and novel potassium and phosphorus solubilizing psychrotolerant bacteria. In: Proceeding of 55th Assoction of Microbiologist and National Conference on "Empowering Mankind with Microbial Technologies. 2014. 75 p.

5. Yadav AN, Sachan S, Kaushik R, et al. Cold tolerant microbes from Indian Himalayas: diversity and potential applications in biotechnology and agriculture. In: Proceeding of 84th Annual Session of NASI and Symposium on Desert Science-Opportunities and challenges. 2014. p.

6. Yadav AN, Verma P, Sachan S, et al. Microbiome of Indian Himalayan regions: Molecular diversity, phylogenetic profiling and biotechnological applications. In: Proceeding of 86th Annual Session of NASI \& Symposium on "Science, Technology and Entrepreneurship for Human Welfare in The Himalayan Region. 2016. 58 p.

7. Shukla L, Suman A, Yadav AN, et al. Syntrophic microbial system for ex-situ degradation of paddy straw at low temperature under controlled and natural environment. J App Biol Biotech. 2016;4(2):30-37.

8. Yadav AN, Sachan SG, Verma P, et al. Prospecting cold deserts of north western Himalayas for microbial diversity and plant growth promoting attributes. J Bio sci Bioeng. 2015;119(6):683-693.

9. Yadav AN, Sachan SG, Verma P, et al. Culturable diversity and functional annotation of psychrotrophic bacteria from cold desert of Leh Ladakh (India). World J Microbiol Biotechnol. 2015;31(1):95-108.

10. Yadav AN, Kumar V, Kumar K, et al. Current applications and future prospects of eco-friendly microbes. EU Voice. 2017;3(1)1-3.

11. Yadav AN, Verma P, Kumar V, et al. Extreme Cold Environments: A Suitable Niche for Selection of Novel Psychrotrophic Microbes for Biotechnological Applications. Adv Biotechnol Microbiol. 2017;2(2):14.

12. Pandey S, Singh S, Yadav AN, et al. Phylogenetic diversity and characterization of novel and efficient cellulase producing bacterial isolates from various extreme environments. Biosci Biotech Biochem. 2013;77(7):1474-1480

13. Kumar M, Yadav AN, Tiwari R, et al. Deciphering the diversity of culturable thermotolerant bacteria from Manikaran hot springs. Ann Microbiol. 2014;64(2):741-751.

14. Kumar M, Yadav AN, Tiwari R, et al. Evaluating the diversity of culturable thermotolerant bacteria from four hot springs of India. $J$ Biodivers Biopros Dev. 2014;1(27):1-9.

15. Suman A, Verma P, Yadav AN, et al. Bioprospecting for extracellular hydrolytic enzymes from culturable thermotolerant bacteria isolated from Manikaran thermal springs. Res J Biotechnol. 2015;10(4):11.

16. Sahay H, Yadav AN, SinghAK, et al. Hot springs of Indian Himalayas: Potential sources of microbial diversity and thermostable hydrolytic enzymes. 3 Biotech. 2017;7(2):1-11.

17. Kaur R, Saxena A, Sangwan P, et al. Production and characterization of a neutral phytase of Penicillium oxalicum EUFR-3 isolated from Himalayan region. Nus Biosci. 2017;9(1):68-76. 
18. Saxena AK, Kaushik R, Yadav AN, et al. Role of Archaea in sustenance of plants in extreme saline environments. In: 56th Annual Conference of Association of Microbiologists of India and International Symposium on Emerging Discoveries in Microbiology.

19. Yadav AN, Verma P, Kumar S, et al. Actinobacteria from Rhizosphere Molecular Diversity, Distributions and Potential Biotechnological Applications. In: New and Future Developments in Microbial Biotechnology and Bioengineering. 2018. p. 13-41.

20. Ikunaga Y, Sato I, Grond S, et al. Nocardioides sp. strain WSN05-2, isolated from a wheat field, degrades deoxynivalenol, producing the novel intermediate 3-epi-deoxynivalenol. Appl Microbiol Biotechnol. 2011;89(2):419-427.

21. Bal HB, Das S, Dangar TK, et al. ACC deaminase and IAA producing growth promoting bacteria from the rhizosphere soil of tropical rice plants. J Basic Microbiol. 2013;53(12):972-984.

22. Cavalca L, Corsini A, Bachate SP, et al. Rhizosphere colonization and arsenic translocation in sunflower (Helianthusannuus L.) by arsenate reducing Alcaligenes sp. strain Dhal-L. World J Microbiol Biotech. 2013;29(10):1931-1940.

23. Li X, Rui J, Xiong J, et al. Functional potential of soil microbial communities in the maize rhizosphere. PloS one. 2014;9(11):e112609.

24. Ali A, Bashir U, Akhtar N, et al. Characterization of growth promoting rhizobacteria of leguminous plants. Pakistan Journal of Phytopathology. 2016;28(1):57-60.

25. Yadav AK, Srivastava AK, Yandigeri MS, et al. Characterization of indigenous copper-resistant Streptomycetes from chickpea (Cicer arietinum L.) fields. Ann Microbiol. 2010;60(4):605-614.

26. Khan MA, Gangopadhyay S. Effect of Soil Inhabiting Antagonistic Microflora Against f. sp. Incitant of Wilt in Chickpea. J Mycol Plant Pathol. 2012;42(3):341.

27. Martin-Laurent F, Barrès B, Wagschal I, et al. Impact of the maize rhizosphere on the genetic structure, the diversity and the atrazinedegrading gene composition of cultivable atrazine-degrading communities. Plant Soil. 2006;282(1):99-115.

28. Wen X-y, Dubinsky E, Yao W, et al. Wheat, maize and sunflower cropping systems selectively influence bacteria community structure and diversity in their and succeeding crop's rhizosphere. J Integ Agric. 2016;15(8):1892-1902.

29. Carro L, Spröer C, Alonso P, et al. Diversity of Micromonospora strains isolated from nitrogen fixing nodules and rhizosphere of Pisum sativum analyzed by multilocus sequence analysis. Syst Appl Microbiol. 2012;35(2):73-80.

30. Tariq M, Hameed S, Yasmeen T, et al. Molecular characterization and identification of plant growth promoting endophytic bacteria isolated from the root nodules of pea (Pisum sativum L.). World J Microbiol Biotechnol. 2014;30(2):719-725.

31. Prasanna R, Nain L, Pandey AK, et al. Microbial diversity and multidimensional interactions in the rice ecosystem. Arch Agron Soil Sci. 2012;58(7):723-744.

32. Thawai C, Kittiwongwattana C, Thanaboripat D, et al. Micromonospora soli sp. nov., isolated from rice rhizosphere soil. Antonie van Leeuwenhoek. 2016;109(3):449-456.

33. Cattelan A, Hartel P,Fuhrmann J. Bacterial composition in the rhizosphere of nodulating and non-nodulating soybean. Soil Sci Soc Am J. 1998;62(6):1549-1555.

34. El-Tarabily KA, Nassar AH, Sivasithamparam K. Promotion of growth of bean (Phaseolus vulgaris L.) in a calcareous soil by a phosphate- solubilizing, rhizosphere-competent isolate of Micromonospora endolithica. Appl Soil Ecol. 2008;39(2):161-171.

35. Shen Y, Liu C, Wang X, et al. Actinoplanes hulinensis sp. nov., a novel actinomycete isolated from soybean root (Glycine max (L.) Merr) Antonie van Leeuwenhoek. 2013;103(2):293-298.

36. Mayilraj S, Krishnamurthi S, Saha P, et al. Kitasatospora sampliensis sp. nov., a novel actinobacterium isolated from soil of a sugar-cane field in India. Int J Syst Evol Microbiol. 2006;56(3):519-522.

37. De Oliveira ZM, Floh EI, Ferrara FI, et al. Diazotrophyc rhizobacteria isolated from sugarcane can release amino acids in a synthetic culture medium. Biol Fert Soils. 2011;47(8):957-962.

38. Wei F, Lin YY, YE BY, et al. Screening and identifying of xylanase producing strain from sugarcane rhizosphere soil. Sub Agric Res 2011;3:14.

39. Ambrosini A, Beneduzi A, Stefanski T, et al. Screening of plant growth promoting rhizobacteria isolated from sunflower (Helianthus annuus L.). Plant Soil. 2012;356(1-2):245-264.

40. Wang W, Qiu Z, Tan H, et al. Siderophore production by actinobacteria. Biometals. 2014;27(4):623-631.

41. Schoebitz M, Ceballos C, Ciamp L. Effect of immobilized phosphate solubilizing bacteria on wheat growth and phosphate uptake. J Soil Sci Plant Nutr. 2013;13(1):1-10.

42. Verma P, Yadav AN, Khannam KS, et al. Assessment of genetic bacterial diversity and plant growth promoting attributes of drought tolerant K-solubilizing bacteria allied with wheat (Triticum aestivum). In: 84th Annual session of NASI and symposium on Desert ScienceOpportunities and Challenges. Held at Jai Narain Vyas University, Jodhpur, Rajasthan. 2014

43. Verma P, Yadav AN, Khannam KS, et al. Growth promotion and yield enhancement of wheat (Triticum aestivum L.) by application of potassium solubilizing psychrotolerant bacteria In: Proceeding of 56th Annual Conference of Association of Microbiologists of India and International Symposium on Emerging Discoveries in Microbiology. 2016 .

44. Verma P, Yadav AN, Shukla L, et al. Alleviation of cold stress in wheat seedlings by Bacillus amyloliquefaciens IARI-HHS2-30, an endophytic psychrotolerant K-solubilizing bacterium from NW Indian Himalayas. Nal J Life Sci. 2015;12(2):105-110.

45. Dubey G, Kollah B, Gour VK, et al. Diversity of bacteria and archaea in the rhizosphere of bioenergy crop Jatropha curcas. 3 Biotech. 2016;6(2):257.

46. Verma P, Yadav AN, Kumar V, et al. Microbes mediated biofortification of wheat (Triticum aestivum L.) for micronutrients by Fe-chelating and Zn-solubilizing bacteria. In: Proceeding of National Conference on Advances in Food Science and Technology. 2017. 119 p.

47. Peoples MB, Craswell ET. Biological nitrogen fixation: investments, expectations and actual contributions to agriculture. Plant Soil. 1992;141(1-2):13-39.

48. Verma P, Yadav AN, Kazy SK, et al. Evaluating the diversity and phylogeny of plant growth promoting bacteria associated with wheat (Triticum aestivum) growing in central zone of India. Int $J$ Curr Microbiol Appl Sci. 2014;3(5):432-447.

49. Verma P, Yadav AN, Khannam KS, et al. Assessment of genetic diversity and plant growth promoting attributes of psychrotolerant bacteria allied with wheat (Triticum aestivum) from the northern hills zone of India. Ann Microbiol. 2015;65:1885-1899.

50. Giri S, Pati B. A comparative study on phyllosphere nitrogen fixation by newly isolated Corynebacterium sp. \& Flavobacterium sp. and 
their potentialities as biofertilizer. Acta Microbiol Immunol Hung. 2004;51(1-2):47-56.

51. Gtari M, Ghodhbane-Gtari F, Nouioui I, et al. Phylogenetic perspectives of nitrogen-fixing actinobacteria. Arch Microbiol. 2012;194(1):3-11.

52. Karlidag H, Esitken A, Turan M, et al. Effects of root inoculation of plant growth promoting rhizobacteria (PGPR) on yield, growth and nutrient element contents of leaves of apple. Scientia horticulturae. 2007;114(1):16-20.

53. Mahendra S, Alvarez-Cohen L. Pseudonocardia dioxanivorans sp. nov., a novel actinomycete that grows on 1, 4-dioxane. Int J Syst Evol Microbiol. 2005;55(2):593-598

54. Anwar S, Ali B, Sajid I. Screening of rhizospheric actinomycetes for various in-vitro and in-vivo plant growth promoting (PGP) traits and for agroactive compounds. Front Microbiol. 2016;7;1334.

55. Dastager SG, Deepa C, Pandey A. Isolation and characterization of novel plant growth promoting Micrococcus sp NII-0909 and its interaction with cowpea. Plant Physiol Biochem. 2010;48(12):987-992.

56. Singh P, Kumar V, Agrawal S. Evaluation of phytase producing bacteria for their plant growth promoting activities. Int J Microbiol. 2014.

57. Singh RN, Gaba S, Yadav AN, et al. First, High quality draft genome sequence of a plant growth promoting and Cold Active Enzyme producing psychrotrophic Arthrobacter agilis strain L77. Stand Genomic Sci. 2016;1-11.

58. Verma P, Yadav AN, Kazy SK, et al. Elucidating the diversity and plant growth promoting attributes of wheat (Triticum aestivum) associated acidotolerant bacteria from southern hills zone of India. Natl J Life Sci. 2013;10(2):219-227.

59. Tiwari S, Singh P, Tiwari R, et al. Salt-tolerant rhizobacteria-mediated induced tolerance in wheat (Triticum aestivum) and chemical diversity in rhizosphere enhance plant growth. Biology and Fertility of soils. 2011;47(8):907.

60. Verma P, Yadav AN, Khannam KS, et al. Appraisal of diversity and functional attributes of thermotolerant wheat associated bacteria from the peninsular zone of India. Saudi J Biol Sci. 2016.

61. Burg RW, Miller BM, Baker EE, et al. Avermectins, new family of potent anthelmintic agents: producing organism and fermentation. Antimicrob Agent Chem. 1979;15(3):361-367.

62. Ando K, Oishi H, Hirano S, et al. Tetranactin, a new miticidal antibiotic: i. Isolation, characterization and properties of tetranactin. $J$ Antibiot. 1971;24(6):347-352.

63. Waller PJ, Faedo M. The prospects for biological control of the freeliving stages of nematode parasites of livestock. Int $J$ Parasitol. 1996;26(8-9):915-925.

64. Tomilova OG, Kryukov VY, Duisembekov BA, et al. Immunephysiological aspects of synergy between avermectins and the entomopathogenic fungus Metarhizium robertsii in Colorado potato beetle larvae. J Invert Pathol. 2016;140:8-15.

65. Khan RA, Naveed M. Evaluation of Comparative Toxicity of Different Insecticides against Fruit Fly, Bactrocera zonata Saunders (Diptera: Tephritidae). Pak J Zool. 2017;49(11).

66. Sharma G, Mehta S. Trends, Growth and Instability in Area, Production and Productivity of Maize Crop across Regions in India. Productivity. 2016;56(4):368

67. Verma P, Yadav AN, Kumar V, et al. Microbes in Termite Management: Potential Role and Strategies. In: Sustainable Termite Management. Springer, New York. 2017. 